\title{
Transcolonic pelvic abscess drainage
}

\author{
S Beningfield, MB ChB, FFRad (D) \\ Department of Radiology, University of Cape Town \\ P Goldberg, MB ChB, FCS (SA), MMed \\ Division of Surgery, Groote Schuur Hospital, Cape Town
}

Although there are a number of reports of successful drainage of deep pelvic collections using transrectal, transvaginal, transgluteal and other routes, ${ }^{1,2}$ some collections remain difficult to access.

An elderly female patient with renal failure presented with features of sepsis following a partial sigmoid colectomy for diverticular disease, with a left iliac fossa colostomy in place. A left pelvic sidewall collection was demonstrated by CT scanning (Fig. 1), but was not felt to be accessible by the usual routes. A standard lower abdominal or pelvic approach was not possible because of overlying loops of bowel. The collection was too high and small for transgluteal or anterolateral approaches, added to which, the left iliac fossa colostomy further limited any approaches. Following a suggestion by one of the authors (PG), an attempt was made to drain the collection under fluoroscopy, using a transcolonic access route.

The patient was sedated and laid left side down in a left decubitus position, and the catheter was introduced per rectum with the aid of lubricating gel and a guiding finger. An initial attempted passage through the rectosigmoid with a headhunter catheter and hydrophilic guidewire was complicated by the somewhat tortuous sigmoid colon and the residual diverticulae. The catheter was very inclined to enter the diverticulae and stretch them, but by retraction and rotation, the main lumen could be re-entered. Some diverticulae were noted to contain concretions, presumably faecoliths. Gentle rotation, supplemented by intermittent contrast injections, hydrophilic guidewires and cobra catheters eventually allowed entry into the pelvic sidewall collection (Fig. 2), presumably through a previously perforated diverticulum that may have led to the abscess in the first place. Using an exchange wire, a standard $8 \mathrm{~F}$ locking pigtail catheter was placed in the collection, with withdrawal of approximately $200 \mathrm{ml}$ of pus. The hub of the catheter was secured in the gluteal cleft, and the patient's features of sepsis improved over subsequent days. The catheter appeared well tolerated by the patient.

After a few weeks, the pigtail was accidentally dislodged. This was replaced with a longer internal-external drainage catheter which was again retained by locking the pigtail. Again purulent material was obtained from the collection, with clinical improvement.

This technique provides an alternative method for draining deep pelvic sidewall collections, but is probably only applicable where there is a breach in the colonic wall, as when the source of sepsis is the sigmoid colon, or the sepsis erodes into the colon.

1. Loren I, Lasson A, Lundagards I, Nilsson A, Nilsson PE. Transrectal catheter drainage of deep abdominal and pelvic abscesses using combined ultrasonography and fluoroscopy. Eur J Surg 2001; 167: 535-539. 2. Gupta S, Madoff DC, Ahrar K, et al. CT-guided needle biopsy of deep pelvic lesions by extraperitoneal approach through iliopsoas muscle. Cardiovasc Intervent Radiol 2003; 26: 534-538.

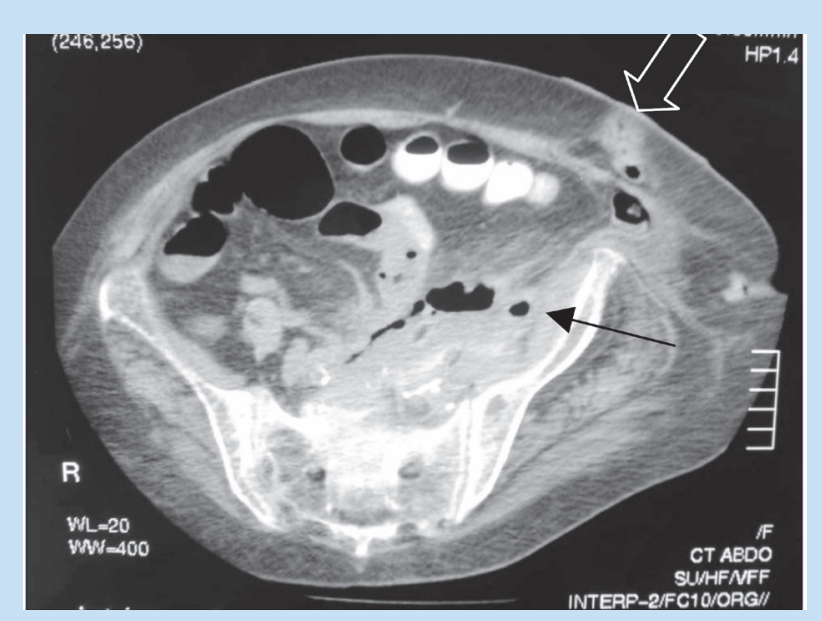

Figs. 1. CT scan showing the pelvic sidewall collection containing gas (arrow). Note left colostomy site (open arrow) blocking anterolateral access.
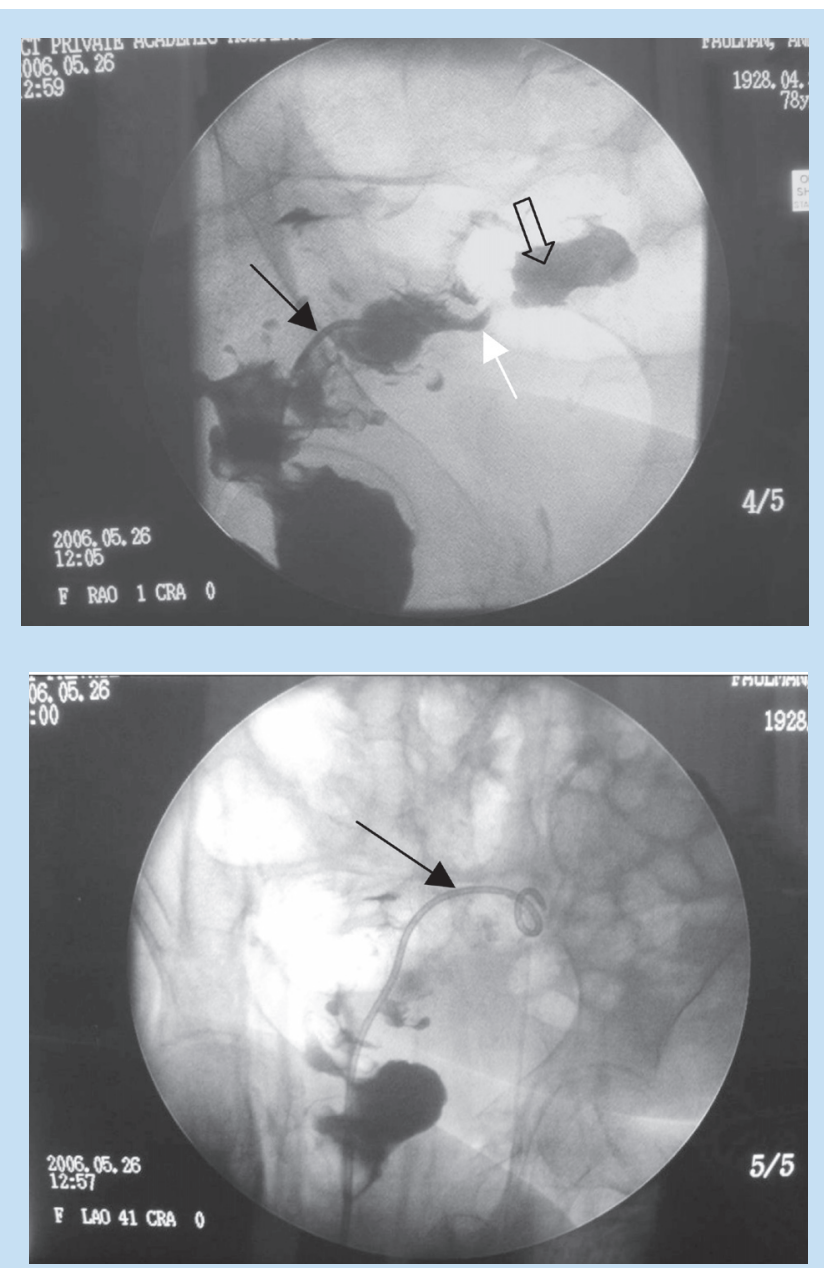

Fig. 2 a and b. Fluoroscopic image (a) during catheter (black arrow) manipulation showing pelvic sidewall collection (open arrow) apparently arising from diverticulum (white arrow) and (b) after placement of the drainage catheter (arrow). 